\title{
How to improve the continuing professional development in Korea
}

Myung Jin Lee

Korean Medical Ethics Study Group

Continuing professional development (CPD) is a broader concept of an educational program than continuing medical education (CME), which is currently considered as supplementary or training education. Whereas CME, only focuses on medical knowledge and skills, CPD goes step further to provide the opportunities for doctors to continuously acquire competence in professionalism and techniques required to perform medical practice. CPD is designed for all doctors, especially medical school professors, employed doctors, self-occupied physicians, and other medical related field workers with medical licenses. The requirements or conditions for successful reformation from $\mathrm{CME}$ to $\mathrm{CPD}$ in Korea were primary concern for Korean Medical Association (KMA). Most importantly, the instructors of CPD must be fully aware of its concept. With such given, education guideline, facilities management, certification, and other management should follow the CPD formation.

\section{The three major components for successful CPD adaptation}

\section{CPD program development}

1) Code of ethics, ethical guidelines and professionalism for doctors

The initial stage of CPD development is the establishment of the Medical Code of Ethics and Medical Ethical Guidelines, which reflects their professionalism. A doctor's code of ethics and ethical guidelines form the basic frame of $\mathrm{CPD}$, stipulating the values of medical association, ideal self-image as a doctor, responsibility, minimum rules of conduct, and so on. Generally, most of the other countries enact a code of ethics that has multiple functions such as value-orientedness, educational, managerial, auto-regulatory function. The currently used Code of Ethics and ethical guidelines was revised in 2006, in the same year that the KMA abolished Medical Declaration of Ethics, which was established in 1997. A total of five chapters and 33 articles of Code of
Received: January 4, $2016 \bullet$ Revised: February 12, $2016 \bullet$ Accepted: February 12, 2016 Corresponding Author: Myung Jin Lee (http://orcid.org/0000-0001-9076-7771)

1384 Nambusunhwan-ro, Geumcheon-gu, Seoul 08547, Korea

Tel: +82.10.5259.5795 Fax:+82.2.865.5527 email:papa5795@hanmail.net
Korean J Med Educ 2016 Jun; 28(2): 153-156.

http://dx.doi.org/10.3946/kjme.2016.27

eISSN: 2005-7288

(C) The Korean Society of Medical Education. All rights reserved. This is an open-access article distributed under the terms of the Creative Commons Attribution Non-Commercial License (http:// creativecommons.org/licenses/by-nc/3.0/), which permits unrestricted non-commercial use, distribution, and reproduction in any medium, provided the original work is properly cited. 
Ethics were reformed as eight articles, and in 2001, six chapters and 78 articles of ethical guidelines were shortened to 30 articles. The major problem of this reformation is professional ethics part, which for the most part is excluded, even as it is the foundation for the professionalism. To develop a practical education program with a focus on medical professionalism makes the delayed consequent revision of both the Code of Ethics and ethical guidelines indispensable. A new revision meeting the demands of time specific to Korea's current medical situation, and a clearer role of the professionalism that is future oriented is essential. Based on a structurally well reformed ethical guideline, practice standards must be settled in the field by going beyond applying indefinite concepts provided from overseas, by providing and preparing new and suitable standards. What we need is a customized standard that fits Korea's current situation. It should not be overly idealistic, but should have an achievable target that can motivate doctors. The education program without a concrete framework will end up as an ambiguous plan. Moreover, the regular revision is another important job to keep an effective ethical guidelines and provide practice standards. Providing updated and efficient education contents is the next step for developing CPD in order for the doctors to sustain high quality service and treatment.

2) Developing program for common ground and specialty

First, the current CME education organization should have a clear understanding on CPD's concepts and contents before initiating the program. The well-designed contents of education program should be prepared to generate doctors who can apply and effectively practice the knowledge they have acquired through their occupation. The necessary information containing contents needs to be divided into two parts, i.e., common ground and major specialty. Common ground part is consisted with mostly fundamental ethical guidelines; basic administration management procedure; contagious disease handling and coping plan; first aid; illegal drugs handling information and regulation; and practical guideline, such as the Chaperone Policy. For the major specialties, it requires customized program that suits its design and includes contents such as professional knowledge, technique, doctor's practice guideline in the doctor's office.

\section{Managing education and evaluation institution}

\section{1) Management of $C P D$ provider}

CPD Accreditation Committee needs to provide the most required criteria and encourage CPD provider for their effective management. In particular, finance management must be done under transparent conditions, and conflict of interest should be well considered.

\section{2) Managing and implementing of $\mathrm{CPD} \mathrm{Ac}^{-}$ creditation Committee}

The core values of the training course evaluation group are financial affairs, the authority of human resources, and tenure guarantee. According to the current KMA's of CPD Accreditation Committee operation regulation, Article 2 states that: (1) The Accreditation Committee should be managed as a presidential advisory body and needs to be consistent with the head steering committee and subcommittee. (2) The head of the committee responsible for the general management of the Accreditation Committee is selected from among the vice-chairmen, and the president has the right to assign the position. Article 8: (1) Head of evaluation committee and committee member's tenure is limited to 3 years; and consecutive appointment is possible, except when an executive director's term is deemed to be the same as that of other executive directors. The Accreditation Committee is part of the doctors' union-affiliated organization, and the head of 
the institution is assigned by the head of the doctors' union; in this way, the institution loses its independence. Furthermore, each position's tenure cannot be guaranteed due to the disorganized managerial structure. For the organization's effective management of public confidence, accreditation, and evaluation, an effective independent action plan concerning finance management and authority on human resources is essential. In the end, it is critical for the evaluation institution to be developed continuously as one group that has solidarity and is independent. In addition, it is necessary to establish better evaluation criteria on CDP provider for evaluation of CPD provider. This evaluation criteria's initial stage should consist of the rules that the CPD provider can easily follow and adapt. The criteria can gradually develop into the next stage with more methodical and applicable rules later on.

\section{Accreditation}

CPD provider's accreditation will be built up by:

(1) Providing proper educational content that includes the professionalism

(2) Continuous improvement effort on internal and external evaluation

(3) Evaluation on wholesome finance management and other general affairs

Based on evaluation results of (1)-(3), a differentiated accreditation strategy should be implemented.

\section{The role of CPD program's participants and instructor's competency and methodology in realizing the effective results from the CPD education program}

\section{Qualification and competency on CPD In- structor}

The instructor's competency would be the catalyst in changing the professionalism of doctors through the CPD program. It is essential for the instructor to provide qualified training and understand the CPD's purpose and concept.

\section{Philosophical medical education methodology}

1) Aristotle's virtue ethic states that the highest good that humans should pursue is happiness

This "happiness" can be realized through understanding intellectualism and voluntarism. When we apply philosophical idea of Aristotle's to medical field in an adequate manner, doctors' pursuit of virtue and happiness is to be good doctors by fully equipping themselves with expertise and techniques necessary and fitted to their professionalism. Realizing an idealistic image of a good doctor in the medical field is also CPD's purpose of education. Aristotle added that intellectual virtue can be built up and empowered by practical wisdom, understanding, and philosophical wisdom. However, failing on following what is right and wrong is due to weak volition and this can be improved by adequate habitual practice, which is strongly related to human nature, virtue, and maturity. Continuous repetitious practice embodies the highest virtue of "happiness." "One swallow does not make a summer" said Aristotle, and this is interpreted as "A day practice does not bring true happiness and a single unit education cannot build good 
human nature doctor." Repetitious education will help doctors in reaching the highest career of virtue by being good doctors.

\section{2) Emotionalism and role model}

Instructors in medical school can be absolute influences on their pupils who participate in basic medical education, post graduate medical education, and CPD education. Therefore, it is essential for instructors need to be respectable role models so that students can be inspired to adapt and learn from them. Regardless of excellent program or facility, if the students are not inspired to learn, the effectiveness of education decrease significantly. Thus, applying emotionalism and a philosophical approach - that highly values intellectualism and voluntarism-will be needed. It is said, "Thinking changes action.” Recognizing knowledge after understanding all the collected data will generate action change. In this process, inspiration is indispensable. "A good teacher is not someone who delivers their knowledge with fancy teaching techniques; a true instructor is one who can motivate a learner to love learning." Successful CPD education can be fulfilled by a philosophically grounded medical education with strong inspiration.

ORCID: Myung Jin Lee: http://orcid.org/0000-0001-9076-7771 Acknowledgements: None.

Funding: None.

Conflicts of interest: None. 